\title{
Optically Active Lyotropic Chromonic Liquid Crystal Based on Green Perylene Bisimide
}

\author{
Jaishri J. Naidu, Seunghan Shin, ${ }^{\dagger}$ Kwang-Un Jeong, ${ }^{*}$ and Myong-Hoon Lee ${ }^{*}$ \\ Department of Polymer/Nano Science and Technology, Chonbuk National University, Jeonju, Chonbuk 561-756 Korea \\ "E-mail:kujeong@chonbuk.ac.kr (K.U.J.),mhlee2@chonbuk.ac.kr (M.H.L.) \\ ${ }^{\dagger}$ Korea Institute of Industrial Technology (KITECH), Chonan, Chungnam 330-825, Korea \\ Received May 24, 2010, Accepted July 26, 2010
}

Key Words: Perylene bisimide, Lyotropic chromonic liquid crystal, Color tuning, Optically active liquid crystal

Perylene tetracarboxylic acid bisimide, in short perylene bisimide (PBI) based colorants have received a considerable attention in academic as well as industrial dye and pigment research. ${ }^{1,2}$ Since PBIs are known as the best $n$-type semiconductors available to date, there have been a lot of effort to use them as electronic materials. ${ }^{3,4}$ This $n$-type semi-conductivity is related to the high electron affinity of rylene bisimide dyes ${ }^{5}$ which makes naphthalene, perylene, as well as higher rylene bisimide dyes ${ }^{6}$ most promising for application in organic field effect transistors. ${ }^{7}$ In addition, based on their unique combination of optical and electrochemical properties with outstanding stability, PBI dyes have already been investigated extensively for more than a decade in electrophotography (xerographic photoreceptors) ${ }^{8}$ and photovoltaics. ${ }^{9}$

Recently, PBIs having ionic periphery have attracted much attention since they can form lyotropic chromonic liquid crystalline (LCLC) phase in aqueous solution. In the LCLC phase, the molecules form a self-assembled columnar structure due to the $\pi-\pi$ stacking of aromatic core and the hydrophilic interaction of ionic peripheries at water interface. A growing acceptance of the concept of chromonic phases and a wider recognition that they form a well-defined family of lyotropic liquid crystalline (LC) phases with variety of properties make the LCLCs distinct in almost every aspect from conventional lyotropic liquid crystals such as amphiphiles. ${ }^{10-12}$ The columnar structures selfassembled into oriented LC phase in aqueous solution allow one to use them in various structured films. Examples of such potential applications include the fabrication of light-harvesting devices, ${ }^{13}$ coatable polarizers, ${ }^{14}$ and compensating plates ${ }^{15}$ for improving the viewing characteristics of twisted nematic displays, all fabricated by aligning LCs. Most of the LCLCs are not toxic, and thus, can also be used as an amplifying medium in biosensors. ${ }^{16}$ Even though these technologies may not be yet suitable for commercial exploitation in their present forms, the success of these devices is significant.

When many advantages of PBI were taken into account, color-tuning of PBI dye is one of the key issues especially in optical and photonic applications because colors of PBIs are mostly limited to red or orange. One of the most robust methods to solve this problem is the structural modification of PBIs, especially at the bay area (1,7-position of the perylene core). For example, Stalke et al..$^{17}$ reported a series of compounds with different substituents at bay region of perylene core. Würthner et al. ${ }^{18}$ also reported a series of thermotropic liquid crystals based on PBI dyes with various substituents at the bay area (1,6,7,12-positions of the perylene core). According to their reports, PBI derivatives with electron-donating substituents at the bay area exhibit a large bathochromic shift of the absorption maxima $\left(\lambda_{\max }\right)$, reflecting pronounced electronic interactions between the perylene core and the electron-donating groups at the bay area. In contrast, PBI derivatives with electron-withdrawing substituents such as $\mathrm{Cl}, \mathrm{Br}$, or pentafluorophenoxy groups at the bay positions showed hypsochromic shift of $\lambda_{\max }$. However, structural modification of PBI containing ionic peripheries for the generation of LCLC is synthetically complicated because the resulting PBI molecules often exhibit limited solubility in common organic solvents due to their ionic nature. In addition, the substitution at the bay area can cause a twisting of aromatic core subsequently hindering a $\pi-\pi$ stacking which is crucial for the formation of LC phases. Therefore, it is challenging to design and synthesize new PBI derivatives which have green or blue color, and simultaneously, could form a lyotropic LC phase in aqueous solution.

Recently, we reported the first example of green LCLC molecule based on PBI core. ${ }^{19}$ By introducing bulky and electron donating $N$-pyrrolidine substituent at the bay area (1,7-position) of PBI core, large bathochromic shift of absorption maxima was achieved. We now present new green PBI derivatives containing optically active and racemic ionic peripheries (Figure 1), which show lyotropic liquid crystalline behavior in aqueous solution. Both compounds exhibited remarkably enough longwavelength absorption (green) and good solubility either in organic solvents or in water. For the optically active LCLC compound, especially, it is expected to exhibit a stereo-specificity, which is essential for the recognition of biological molecules by forming columnar LCs with twisted $\pi-\pi$ stacking of aromatic core with a specific handedness.

The syntheses of optically active and racemic green LCLCs are schematically illustrated in Figure 1. Firstly, bromination of perylene dianhydride was performed according to the BASF patent. ${ }^{20}$ The bromination under this condition afforded a mixture of 1,7-and 1,6-dibrominated compounds with trace amount of 1,6,7-tribrominated analogues (1, 2, and $\mathbf{3}$ in Figure 1). The resulting mixture was insoluble in organic solvents, and therefore, could not be purified by any means. The crude mixture was used for the subsequent imidization with (racemic) 2-amino- 


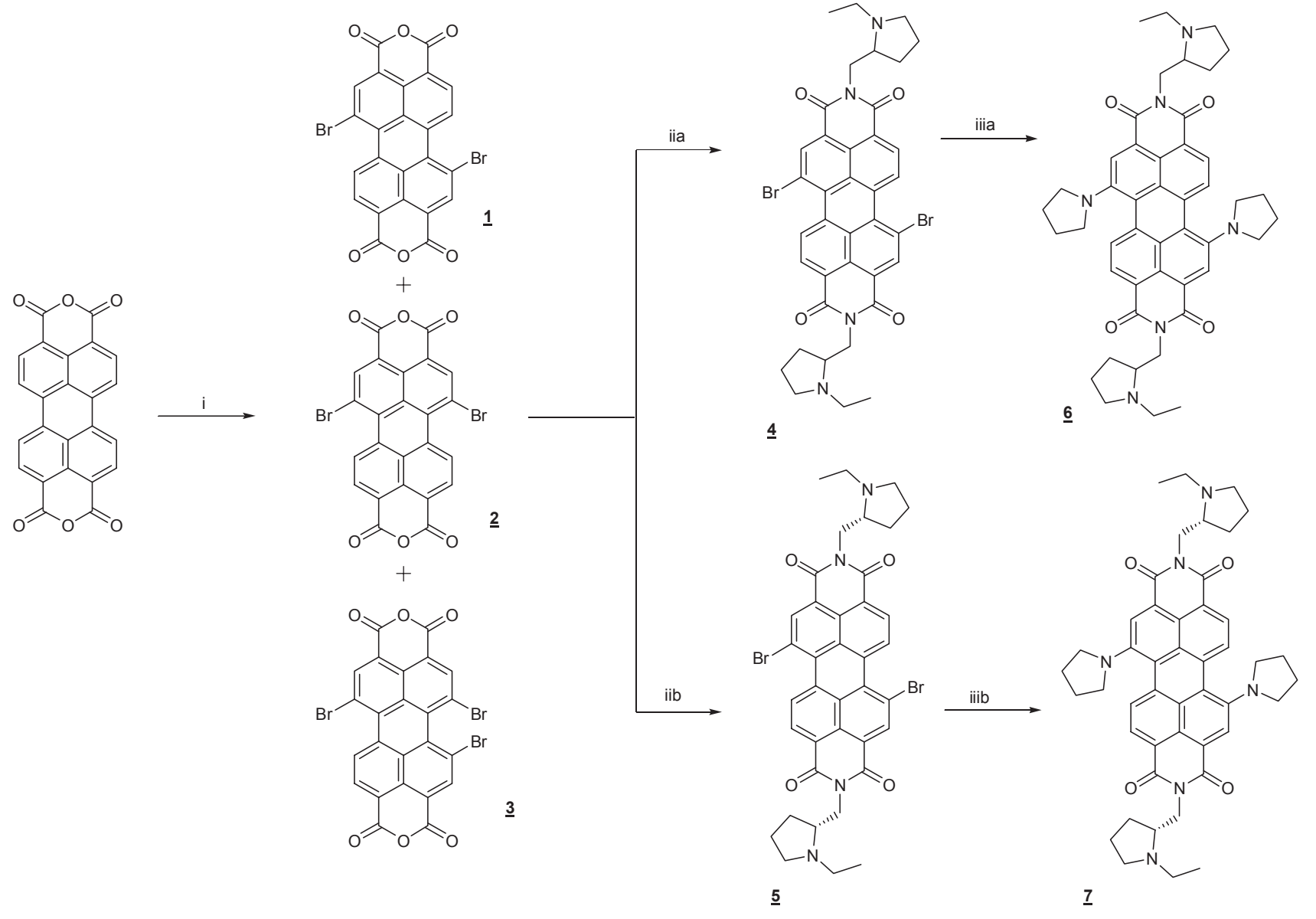

Figure 1. Schematic representation of synthetic route of achiral and chiral perylene bisimide derivatives ( $\mathrm{PBI}$ ): i) $\mathrm{Br}_{2}, \mathrm{I}_{2}$ (catalytic), 100\% $\mathrm{H}_{2} \mathrm{SO}_{4}, 85{ }^{\circ} \mathrm{C}, 12 \mathrm{~h}$; iia) achiral amine, $85{ }^{\circ} \mathrm{C} 12 \mathrm{~h}$; iib) chiral amine, $85{ }^{\circ} \mathrm{C} 12 \mathrm{~h}$; iii) pyrrolidone, $55{ }^{\circ} \mathrm{C}, \mathrm{Ar}, 24 \mathrm{~h}$.

methyl-1-ethylpyrolidine in a mixed solvent of $\mathrm{H}_{2} \mathrm{O} / n$ - $\mathrm{PrOH}$ $(2: 1 \mathrm{v} / \mathrm{v})$ at $80^{\circ} \mathrm{C}$. After the reaction, the product became soluble in organic solvents such as $\mathrm{CH}_{2} \mathrm{Cl}_{2}$ and chloroform, which enabled the separation of regioisomers by column chromatography. From the first chromatography, 1,6,7-tribrominated perylene bisimide was removed (in less than $1 \%$ yield) from the mixture of 1,7- and 1,6-dibrominated compounds. $400 \mathrm{MHz}$ ${ }^{1} \mathrm{H}-\mathrm{NMR}$ analysis of the residual mixture revealed 80:20 ratio of the 1,7- and 1,6-regioisomers. 1,7-Dibrominated compound 4 was separated from this mixture as a major component (in $50 \%$ yield) after the second column chromatography. The nucleophilic substitution of $\mathbf{4}$ with pyrrolidine according to Wasielewski's method ${ }^{21}$ afforded the corresponding 1,7-dipyrrolidinylperylene bisimides (6 in Figure 1) as a green solid in $45 \%$ yield after column chromatography. Similarly we obtained a chiral analogue 7 by using an optically active (s)-(-)-2-(aminomethyl)1-ethylpyrolidine instead of racemic 2-aminomethyl-1-ethylpyrolidine in step (iib) in Figure 1. Detailed synthetic procedures and results of spectroscopic analyses are described in the experimental section. Good solubility either in organic solvents or water, and high thermal stability was observed for both ( \pm )-2-(aminomethyl)-1-ethylpyrrolidine-1,7-dibromoperylene-3,4:9,10-tetracarboxylic acid bisimide (6) and (s)-(-)2-(aminomethyl)-1-ethylpyrrolidine-1,7-dibromoperylene3,4:9,10-tetracarboxylic acid bisimide (7).
The optical properties of bromo- and pyrrolidine-substituted PBIs were investigated by UV-vis spectroscopy as shown in Figure 2. Compounds 4, 6 and 7 in methanol solution exhibited multiple $\mathrm{S}_{0}-\mathrm{S}_{1}$ absorption bands with $\lambda_{\max }$ at 524, 701 and 709 nm, respectively. Compounds 6 and 7 displayed similar absorption spectra. The $\lambda_{\max }$ of bromo-substituted PBI 4 was shifted only slightly from that of the unsubstituted PBI $\left(\lambda_{\max }=527 \mathrm{~nm}\right.$ in $\mathrm{CH}_{2} \mathrm{Cl}_{2}$ ). In contrast, the $\lambda_{\max }$ of compounds $\mathbf{6}$ and 7 showed a large bathochromic shift with exhibiting green color, which is mainly due to the electron-donating pyrrolidine groups directly attached to perylene core at the bay area. Additionally, the band shapes of both compounds $\mathbf{6}$ and 7 were broader as compared to compound 4,5 or unsubstituted PBI, which is probably attributed to the loss of planarity of perylene core due to the steric hindrance at the bay area.

To confirm whether the PBI 7 is optically active or not, circular dichroism spectra were measured for both compounds 6 and 7 as illustrated in Figure 2b. Compared to the racemic compound $\mathbf{6}$ showing only a broad band without any particular peak, the PBI 7 exhibited three apparent bands, two with negative Cotton effect at 341 and $665 \mathrm{~nm}$, and one with positive Cotton effect at $433 \mathrm{~nm}$, respectively. These CD bands clearly support that the chiral PBI 7 is optically active.

Hydrochloride salts of compounds 4, 5, 6 and 7 were dissolved in distilled water (1 wt \%), and their optical textures were 

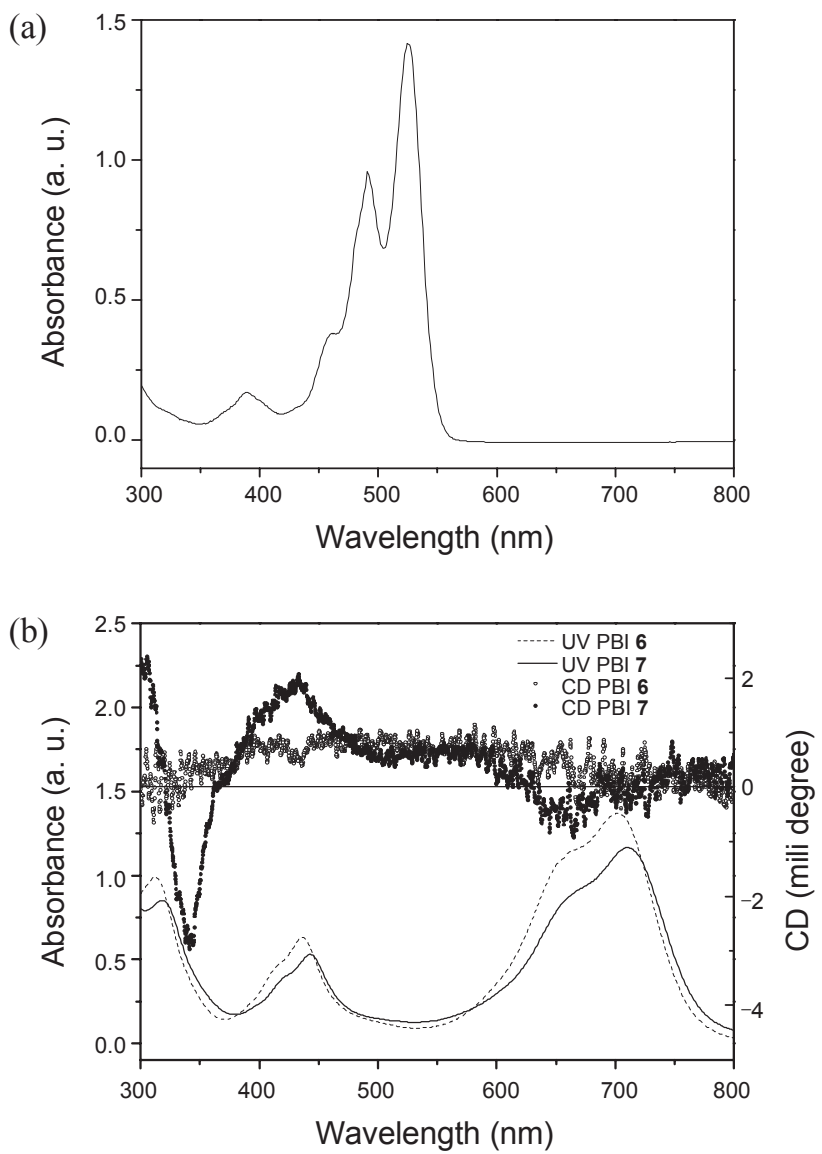

Figure 2. (a) UV-vis absorption spectra (in methanol) of 1,7-dibromosubstituted perylene bisimide (4); (b) UV-vis absorption and CD spectra (in methanol) of 1,7-dipyrrolidine-substituted perylene bisimides (6 and 7$)$.

examined by polarized optical microscope (POM) to confirm whether they have lyotropic LC phase. As depicted in Figure 3, the aqueous solution of compound 4 (Figure $3 a$ ) and compound 6 (Figure $3 b$ and $3 c$ ) formed nematic phase, whereas the compound 7 exhibited texture of chromonic $\mathrm{N}$ phase (Figure $3 \mathrm{~d}$ ). All of the sample solutions flow like a liquid exhibiting birefringences under POM, which clearly indicates that they are truly lyotropic LCs. Würthner et al. reported that the substitution with bulky groups such as pyrrolidine at the bay area results in the twisting of aromatic core which could hinder a $\pi-\pi$ stacking. ${ }^{18}$ It is interesting, however, to note that the PBI molecules synthesized in this work still assemble into stacks of columnar aggregates subsequently forming a nematic LC phase due to the hydrophobic nature of the aromatic central core and the hydrophilic periphery. Further characterization of their LC behavior and structural analyses including X-ray diffraction and phase diagram studies are now in progress.

In summary, we reported the syntheses of the first green and optically active lyotropic chromonic liquid crystalline compound and its racemic analogue based on perylene bisimide. The color-tuning of perylene bisimide was achieved by substituting bulky and electron-donating dipyrrolidine moieties at the bay area. Optical activity was obtained by introducing chiral amine peripheries to perylene bisimide. The resulting com-
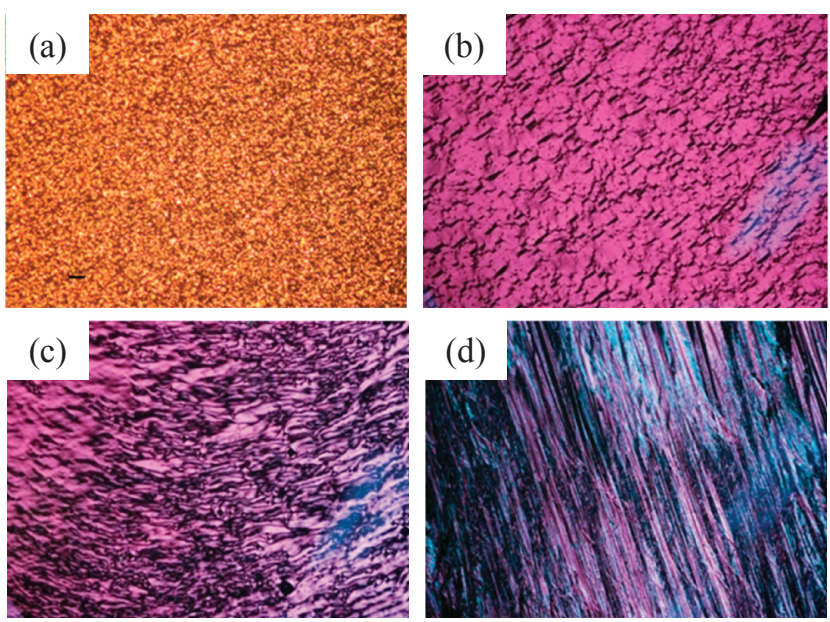

Figure 3. Polarized optical microscope images $(100 \times)$ of perylene bisimides (1.0 wt \% aq. solution) at room temperature: (a) bromosubstituted perylene bisimide (4); (b) and (c) achiral pyrrolidinesubstituted perylene bisimide (6); (d) chiral pyrrolidine-substituted perylene bisimide (7).

pounds exhibited good thermal stability with moderate solubility either in water or in organic solvents. The compounds were characterized by ${ }^{1} \mathrm{H}-\mathrm{NMR},{ }^{13} \mathrm{C}-\mathrm{NMR}$, mass, circular dichroism and UV-vis spectroscopies. Especially, the chromonic perylene bisimide dye containing chiral amine groups at the periphery was optically active, which was confirmed by circular dichroism spectroscopy. Aqueous solutions of their hydrochloride salts showed LCLC phases as confirmed by POM at room temperature. We expect the green and optically active LCLC compound could find many applications such as circularly dichroic coatable polarizers or sensing of biological molecules via a stereospecific binding.

\section{Experimental Section}

Synthetic procedure for compounds $\mathbf{4}$ and 5. A mixture of perylene-3,4:9,10-tetracarboxylic acid (15.65 g, $80.0 \mathrm{mmol})$ and $98 \%$ sulfuric acid (236 g) was stirred for $12 \mathrm{~h}$ at room temperature, and $\mathrm{I}_{2}(0.385 \mathrm{~g}, 3.0 \mathrm{~mol})$ was added subsequently. The reaction mixture was heated to $85^{\circ} \mathrm{C}$, and bromine $(14.1 \mathrm{~g}$, $176 \mathrm{mmol}$ ) was added dropwise over a time period of $8 \mathrm{~h}$. After bromine addition, the reaction mixture was heated for an additional $10 \mathrm{~h}$ at $85^{\circ} \mathrm{C}$ and cooled to room temperature. The excess bromine was removed by a gentle stream of $\mathrm{N}_{2}$ gas, and was added $32.5 \mathrm{~mL}$ of water carefully. The resulting precipitate was separated by filtration through a G4 funnel, washed with $86 \%$ sulfuric acid $(150 \mathrm{~mL})$ and large amount of water, and dried in a vacuum oven to give a crude mixture of 1,7-dibrominated, 1,6-dibrominated and 1,6,7-tribrominated perylene-3,4:9,10tetracarboxylic acid bisimide (1, 2 and $\mathbf{3}$, respectively). A suspension of above mixture $(0.95 \mathrm{~g}, 1.72 \mathrm{mmol}), 2$-(aminomethyl)1-ethylpyrrolidine $(0.502 \mathrm{~g}, 5.07 \mathrm{mmol})$, and acetic acid $(0.50 \mathrm{~g}$, $8.33 \mathrm{mmol}$ ) in $20 \mathrm{~mL}$ of $2: 1$ mixture of $\mathrm{H}_{2} \mathrm{O} / n$-PrOH was stirred at $85{ }^{\circ} \mathrm{C}$ under Ar for $8 \mathrm{~h}$. After the mixture was cooled to room temperature, the precipitate was separated by filtration, washed 
with $100 \mathrm{~mL}$ of $\mathrm{MeOH}$, and dried in vacuum. The crude product was purified by silica gel column chromatography with $\mathrm{CH}_{2} \mathrm{Cl}_{2}$ as eluent. From $400 \mathrm{MHz}{ }^{1} \mathrm{H}$ NMR analysis, the product obtained as a dark brown powder $(755 \mathrm{mg} 60 \%)$ was revealed to be a regioisomeric mixture of 1,7- and 1,6-dibromoperylene bisimides with 80:20 mol ratio, respectively. Second column chromatography gave a pure 1,7-dibromo compound $\mathbf{4}$ (yield = $50 \%$ ) which was confirmed by ${ }^{1} \mathrm{H}$ - and ${ }^{13} \mathrm{C}$-NMR spectra and mass spectroscopy. ${ }^{1} \mathrm{H}-\mathrm{NMR}\left(400 \mathrm{MHz}, \mathrm{CDCl}_{3}\right.$, TMS) $\delta 8.41$ (s, 2H), 8.31 (d, $J=8.1 \mathrm{~Hz}, 2 \mathrm{H}), 7.56(\mathrm{~d}, J=8.1 \mathrm{~Hz}, 2 \mathrm{H}), 5.04-$ $5.10(\mathrm{~m}, 2 \mathrm{H}), 3.65-3.82(\mathrm{~m}, 4 \mathrm{H}), 2.72-2.85(\mathrm{~m}, 4 \mathrm{H}), 2.54-2.66$ $(\mathrm{m}, 4 \mathrm{H}), 1.80-2.9(\mathrm{~m}, 12 \mathrm{H}), 1.73-1.76(\mathrm{~m}, 6 \mathrm{H}), 1.20-1.50(\mathrm{~m}$, $6 \mathrm{H}) ;{ }^{13} \mathrm{C} \mathrm{NMR}\left(100 \mathrm{MHz}, \mathrm{CDCl}_{3}\right) \delta 163.5,163.4,145.4,132.8$, $128.7,125.5,122.6,121.1,119.7,118.4,116.9,52.7,51.0$, 28.1, 25.6, 24.7, 24.5; MS (EI, 70 eV) $\mathrm{m} / \mathrm{z} 770.50$ (100.0\%); UV-vis $(\mathrm{MeOH}) \lambda_{\max } 390,460,490,524 \mathrm{~nm}$.

For the synthesis of chiral compound $\mathbf{5}$, same procedure was adopted except that (s)-(-)-2-(aminomethyl)-1-ethylpyrrolidine $(0.502 \mathrm{~g}, 5.07 \mathrm{mmol})$ was used instead. After the second column chromatography, $\mathbf{5}$ was obtained as a brown powder in $53 \%$ yield. ${ }^{1} \mathrm{H}$ NMR (400 MHz, $\left.\mathrm{CDCl}_{3}, \mathrm{TMS}\right) \delta 8.36(\mathrm{~s}$, $2 \mathrm{H}), 8.35(\mathrm{~d}, J=8.1 \mathrm{~Hz}, 2 \mathrm{H}), 7.58(\mathrm{~d}, J=8.1 \mathrm{~Hz}, 2 \mathrm{H}), 5.04-$ $5.25(\mathrm{~m}, 2 \mathrm{H}), 3.67-3.85(\mathrm{~m}, 4 \mathrm{H}), 2.75-2.89(\mathrm{~m}, 4 \mathrm{H}), 2.56-2.68$ $(\mathrm{m}, 4 \mathrm{H}), 1.82-2.12(\mathrm{~m}, 12 \mathrm{H}), 1.76-1.78(\mathrm{~m}, 6 \mathrm{H}), 1.21-1.53(\mathrm{~m}$, $6 \mathrm{H}) ;{ }^{13} \mathrm{C} \mathrm{NMR}\left(100 \mathrm{MHz}, \mathrm{CDCl}_{3}\right) \delta 163.5,163.4,145.4,132.8$, $128.7,125.5,122.6,121.1,119.7,118.4,116.9,52.7,51.0$, 28.1, 25.6, 24.7, 24.5; MS (EI, $70 \mathrm{eV}) \mathrm{m} / \mathrm{z} 770.51$ (100.0\%); UV-Vis (MeOH): $\lambda_{\max } 388,456,491,524 \mathrm{~nm}$.

Synthetic procedure for compounds 6 and 7. A mixture of $95.0 \mathrm{mg}(0.133 \mathrm{mmol})$ of 1,7-dibromobisimide (4) and $4.30 \mathrm{~g}$ $(59.7 \mathrm{mmol})$ of pyrrolidine was stirred under Ar for $24 \mathrm{~h}$ at $55^{\circ} \mathrm{C}$ (external). Subsequently, the reaction mixture was poured into $15 \mathrm{~mL}$ of $12 \% \mathrm{HCl}$ with stirring. The mixture was extracted with methylene chloride $(3 \times 20 \mathrm{~mL})$, dried over $\mathrm{MgSO}_{4}$, and concentrated by rotary evaporation. The resulting precipitate was purified by column chromatography on silica gel $\left(\mathrm{CH}_{2} \mathrm{Cl}_{2} /\right.$ hexane $(40 / 1, \mathrm{v} / \mathrm{v}))$ to yield $62 \mathrm{mg}(45 \%)$ of a green solid (6). ${ }^{1} \mathrm{H}-\mathrm{NMR}\left(400 \mathrm{MHz}, \mathrm{CDCl}_{3}\right.$, TMS) $\delta$ 8.383-8.30 (d, 2H, $J=$ $8.1 \mathrm{~Hz}), 8.31$ (s, 2H), 7.45 (d, 2H, $J=8.1 \mathrm{~Hz}), 4.4$ (q, 4H), 23.5 $(\mathrm{m}, 5 \mathrm{H}), 3.08(\mathrm{t}, 3 \mathrm{H}), 2.85(\mathrm{q}, 4 \mathrm{H}), 2.2(\mathrm{t}, 3 \mathrm{H}), 1.93(\mathrm{t}, 3 \mathrm{H})$, 1.67 (q, 4H), $1.64(\mathrm{~m}, 5 \mathrm{H}), 1.2(\mathrm{t}, 3 \mathrm{H}) ;{ }^{13} \mathrm{C} \mathrm{NMR}(100 \mathrm{MHz}$, $\left.\mathrm{CDCl}_{3}\right) \delta 159.4,152.9,137.9,133.0,131.5,130.9,129.8,129.2$, 126.5, 124.5, 118.0, 57.8, 55.4, 46.7, 38.0, 29.3, 23.4, 13.6; MS (EI, $70 \mathrm{eV}) \mathrm{m} / z 750.35$ (100\%) [M+]; UV-vis (MeOH) $\lambda_{\max } 311,434,657,701 \mathrm{~nm}$.

For the synthesis of compound 7, compound 5 was used instead of 4 , and the rest of the procedure was the same. Green solid was obtained with a yield of $51 \mathrm{mg}(37 \%)$. Similar spectral data were obtained for ${ }^{1} \mathrm{H}$ and ${ }^{13} \mathrm{C}$ NMRs. MS (EI, $70 \mathrm{eV}$ ) $\mathrm{m} / \mathrm{z}$ $750.38(100 \%)[\mathrm{M}+]$; UV-vis $(\mathrm{MeOH}) \lambda_{\max } 316,442,660$, $709 \mathrm{~nm}$.

Acknowledgments. This work was supported by the Korea Research Foundation Grant funded by the Korean Government
(MOEHRD, Basic Research Promotion Fund) (KRF-2008I00675A). JJN acknowledges for the financial support by grant of the Post-doc Program, Chonbuk National University 2007. SHS is also grateful for the financial support from the Fundamental R\&D Program for Core Technology of Materials funded by the Ministry of Knowledge Economy, Republic of Korea.

\section{References}

1. Zollinger, H. In Color Chemistry, 3rd ed.; VCH: Weinheim, 2003.

2. Herbst, W.; Hunger, K. Industrial Organic Pigments: Production, Properties, and Applications, 2nd ed.; WILEY-VCH: Weinheim, 1997.

3. Struijk, C. W.; Sieval, A. B.; Dakhorst, J. E. J.; Van Dijk, M.; Kimkes, P.; Koehorst, R. B. M.; Donker, H.; Schaafsma, T. J.; Picken, S. J.; van de Craats, A. M.; Warman, J. M.; Zuilhof, H.; Sudhölter, E. J. R. J. Am. Chem. Soc. 2000, 122, 11057.

4. Dimitrakopoulos, C. D.; Malenfant, P. R. L. Adv. Mater. 2002, 14, 99.

5. Lee, S. K.; Zu, Y.; Herrmann, A.; Geerts, Y.; Müllen, K.; Bard, A. J. J. Am. Chem. Soc. 1999, 121, 3513.

6. Quante, H.; Müllen, K. Angew. Chem., Int. Ed. 1995, 34, 1323.

7. Würthner, F. Angew. Chem., Int. Ed. 2001, 40, 1037.

8. Law, K.-Y. Chem. Rev. 1993, 93, 449.

9. a) Schmidt-Mende, L.; Fechtenkötter, A.; Müllen, K.; Moons, E.; Friend, R. H.; MacKenzie, J. D. Science 2001, 293, 1119. b) Yakimov, A.; Forrest, S. R. Appl. Phys. Lett. 2002, 80, 1667.

10. Lydon, J. In Handbook of Liquid Crystals; Vol. 2B, Demus, D., Goodby, J., Gray, G. W., Spiess, H.-W., Vill, V., Eds.; Wiley-VCH: Weinheim, 1998; pp 981-1007 and references therein.

11. a) Lydon, J. Curr. Opin. Colloid Interface Sci. 1998, 3, 458. b) ibid. 2000, 48, 480.

12. Vasilevskaya, A. S.; Generalova, E. V.; Sonin, A. S. Russ. Chem. Rev. 1989, 58, 904.

13. Gustand, D.; Moore, T. A. Science 1989, 244, 35.

14. a) Ichimura, M.; Kudo, K. M.; Akiyama, H.; Ishizuki, N. Langmuir 1995, 11, 2341. b) Matsunaga, D.; Tamaki, T.; Akiyama, H.; Ichimura, K. Adv. Mater. 2002, 14, 1477. c) Tam-Chang, S.-W.; Seo, W.; Iverson, I. K.; Casey, S. M. Angew. Chem., Int. Ed. 2003, 42, 897. d) Iverson, I. K.; Tam-Chang, S.-W. J. Am. Chem. Soc. 1999, 121, 5801. e) Carson, T. D.; Seo, W.; Tam-Chang, S.-W.; Casey, S. M. Chem. Mater. 2003, 15, 2292. f) Iverson, I. K.; Casey, S. M.; Seo, W.; Tam-Chang, S.-W.; Pindzola, B. A. Langmuir 2002, 18 , 3510.

15. Lydon, J. Curr. Opin. Colloid Interface Sci. 2004, 8, 480.

16. a) Shiyanovskii, S. V.; Lavrentovich, O. D.; Schneider, T.; Ishikawa, T.; Smalyukh, I. I.; Woolverton, C. J.; Niehaus, G. D.; Doane, K. J. Mol. Cryst. Liq. Cryst. 2005, 434, 587. b) Shiyanovskii, S. V.; Schneider, T.; Smalyukh, I. I.; Ishikawa, T.; Niehaus, G. D.; Doane, K. J.; Woolverton, C. J.; Lavrentovich, O. D. Phys. Rev. E 2005, 71, 020702R. c) Woolverton, C. J.; Gustely, E.; Li, L.; Lavrentovich, O. D. Liq. Cryst. 2005, 32, 417.

17. Würthner, F.; Stepanenko, V.; Chen, Z.; Saha-Möller, C. R.; Kocher, N.; Stalke, D. J. Org. Chem. 2004, 69, 7933.

18. Chen, Z.; Baumeister, U.; Tschierske, C.; Würthner, F. Chem. Eur. J. 2007, 13, 450.

19. Naidu, J. J.; Bae, Y. J.; Jeong, K.-U.; Shin, S.; Lee, M.-H. Bull. Korean Chem. Soc. 2009, 30(1), 224.

20. Böhm, A.; Arms, H.; Henning, G.; Blaschka, P. (BASF AG) DE 19547209 A1, 1997 [Chem. Abstr. 1997, 127, 96569g].

21. Zhao, Y.; Wasielewski, M. R. Tetrahedron Lett. 1999, 40, 7047. 